ARTIGO

\title{
O TRABALHO DOCENTE NA REDE ESTADUAL DE SÃO PAULO: MAPEAMENTO E ANÁLISE DAS TESES E DISSERTAÇÕES (1996 A 2018)
}

\author{
NATHALIA DE ASSIS SILVA ${ }^{1}$ \\ ORCID: https://orcid.org/0000-0003-1670-4160 \\ MARIA JOSÉ DA SILVA FERNANDES ${ }^{2}$ \\ ORCID: https://orcid.org/0000-0002-4747-6570
}

\begin{abstract}
RESUMO: O artigo traz resultados de uma pesquisa de revisão bibliográfica, quali-quantitativa, que analisou um conjunto formado por 134 pesquisas, teses e dissertações, produzidas nos principais Programas de Pós-Graduação em Educação do estado de São Paulo que tiveram como foco o trabalho docente. A pesquisa considerou o recorte temporal de 1996 a 2018, período que coincide com a implantação de medidas reformistas de natureza neoliberal na rede pública paulista de ensino. Os objetivos do artigo são: a) analisar a produção acadêmica - teses e dissertações - sobre o trabalho docente à luz das reformas educacionais no estado de São Paulo no período de 1996-2018; b) identificar as etapas e as modalidades de ensino abordadas nas teses e dissertações; c) mapear os principais Programas de PósGraduação nos quais são produzidas as pesquisas; d) reconhecer as principais abordagens metodológicas presentes nas teses e dissertações; e) identificar as concepções de trabalho docente presentes nas produções acadêmicas; f) apresentar os principais eixos de análise das pesquisas produzidas no período. Os resultados apontaram os efeitos no cotidiano escolar de uma política que há anos implanta medidas de cima para baixo, com ações, dentre outras, de padronização curricular e regulação por meio de avaliações externas - medidas que não deixaram o trabalho docente incólume e que, além de alterar as possibilidades de constituição de um processo de autonomia, modificaram negativamente suas condições e relações de trabalho. O resultado central da investigação também indicou a ampliação e a consolidação do trabalho docente como campo específico de pesquisa na área da educação.
\end{abstract}

Palavras-chave: Trabalho docente, reformas educacionais, estado de São Paulo, revisão bibliográfica.

\section{TEACHING WORK IN SÃO PAULO STATE: ANALYSIS OF THESES AND DISSERTATIONS (1996 TO 2018)}

\begin{abstract}
The present article presents the results of a bibliographic quali-quantitative research, which analyzed a group of 134 studies, thesis and dissertations, produced in the main Education Graduate Programs in the state of São Paulo which focused on teachers' work. The research considered the time frame from 1996 to 2018, which coincides with the implementation of neoliberal reform measures in the

\footnotetext{
1 Programa de Pós-Graduação em Educação Escolar da Universidade Estadual Paulista. Araraquara, SP, Brasil. $<$ Nathalia.assis.silva92@hotmail.com>

2 Programa de Pós-Graduação em Educação Escolar da Universidade Estadual Paulista. Araraquara, SP, Brasil. <mj.fernandes@unesp.br>
} 
public education system of the state São Paulo. The objectives of this article are: a) analyze the academic production - thesis and dissertations - related to teachers' work given the educational reform in the state in said period - 1996-2018; b) identify the steps and types of teaching approached in the thesis and dissertations; c) map the main Graduate Programs in which the studies are being produced; d) recognize the main methodological approaches used; e) identify concept of teachers' work used in these academic works; f) present the main analytical axis produced in that period. The result of this study presented the effect in school's daily life of a policy that, for years, has been implemented from the top to the bottom, with actions such as the curricula standardizations and the regulation through external evaluations. Measurements which do not leave teachers' work unscathed and that, besides altering their possibilities of establishing an autonomous process, negatively modified their work conditions and relations. The main result of this investigation indicates a growth and consolidation of teachers' work as a specific field of research in the education area.

Keywords: Teachers' work, educational reform, state of São Paulo, bibliographic review.

\section{EL TRABAJO DOCENTE EN EL ESTADO DE SÃO PAULO: ANÁLISIS DE TESIS Y DISERTACIONES (1996 A 2018)}

RESÚMEN: El artículo presenta los resultados de revisión bibliográfica, cualitativa y cuantitativa, que analizó 134 investigaciones acerca del trabajo docente, tesis y disertaciones, producidas en los principales Programas de Posgrado en Educación en el estado de São Paulo. La revisión consideró el período entre 1996 y 2018, que coincide con la implementación de medidas reformistas de carácter neoliberal en el sistema público de São Paulo. Tenemos como objetivos: a) analizar la producción académica - tesis y disertaciones - sobre el trabajo docente en el estado de São Paulo en el período 1996-2018; b) identificar las etapas y modalidades de enseñanza en las tesis y disertaciones; c) mapear los principales programas de posgrado en los que se produce la investigación acerca del trabajo docente; d) reconocer los principales enfoques metodológicos presentes en tesis y disertaciones; e) identificar las concepciones del trabajo docente presente en producciones académicas; f) presentar los principales ejes de análisis de las investigaciones producidas en el período. Los resultados señalaron los efectos en la vida escolar de una política que durante años ha implementado medidas de arriba para abajo, con acciones, entre otras, de estandarización y regulación curricular a través de evaluaciones externas. Medidas que no dejaron ileso el trabajo docente y que, además de alterar sus posibilidades de constituir un proceso de autonomía, cambiaron negativamente sus condiciones y relaciones laborales. El resultado central de la investigación también indicó la expansión y consolidación del trabajo docente como un campo específico de investigación en el área de la educación.

Palabras clave: Trabajo docente, reformas educacionales, estado de São Paulo, revisión bibliográfica.

\section{INTRODUÇÃO}

O contexto político e econômico que o Brasil vivenciou ao longo da segunda metade da década de 1990 foi marcado por reformas nos mais diversos setores, dentre eles, o educacional. Para Hypólito (2011), a adoção de medidas reformistas na educação faz parte de um novo tipo de Estado de natureza gerencialista, também denominado Nova Gestão Pública (NGP). No campo educacional, especificamente, as políticas neoliberais consideram a educação como uma mercadoria a ser negociada no âmbito do capitalismo. Para Ball (2005, p. 544), autor que discute as reformas educacionais neoliberais em diferentes partes do mundo, "o gerencialismo desempenha o importante papel de destruir os sistemas ético-profissionais que prevaleciam nas escolas, provocando sua substituição por sistemas empresariais competitivos". Nesse cenário, a escola articulou-se à economia e aos padrões empresariais de 
organização, relativizando a ação transmissora do conhecimento frente à capacitação para o mercado. As mudanças nas concepções e práticas provocaram alterações significativas no trabalho docente.

No caso específico do estado de São Paulo, as reformas educacionais de natureza neoliberal tomaram corpo a partir da chegada do Partido da Social Democracia Brasileira (PSDB) ao poder, em 1995, iniciando-se as primeiras e significativas medidas educacionais no ano de 1996. Desse momento primevo até os dias atuais, foram implantadas intensas e sucessivas medidas na rede estadual. O conjunto de medidas, mesmo com diferentes governadores e em representativo intervalo de tempo, foi coerente com os princípios da NGP, indicando articulação, aprofundamento e complexificação das ações que, direta e indiretamente, impactaram o trabalho docente.

O trabalho docente, conceito e objeto central de análise deste artigo, é compreendido como complexo e "[...] parte da totalidade constituída pelo trabalho no capitalismo, estando submetido, portanto, à sua lógica e às suas contradições" (DUARTE, 2011, p.163). Assim, é uma categoria analítica central nas investigações que tratam as reformas realizadas no âmbito da educação, especialmente escolar, que afetam profundamente as escolas e os trabalhadores. Dessa maneira, estabelecemos como recorte de análise as pesquisas acadêmicas realizadas sobre o trabalho docente no estado de São Paulo, unidade da federação que tem no governo um mesmo partido político há seis mandatos e que concentra o maior número de escolas e de docentes do País, assim como programas de Pós-Graduação em Educação. Um questionamento central conduziu à seguinte investigação: o que as teses e dissertações produzidas nos Programas de Pós-Graduação no estado de São Paulo apresentam sobre o trabalho docente no contexto das reformas educacionais neoliberais ocorridas nas duas últimas décadas? Tal questão se desdobrou em outras indagações: quais as etapas e modalidades de ensino que as teses e dissertações abrangem? Onde são produzidas as pesquisas sobre trabalho docente no estado de São Paulo? Quais são as principais abordagens metodológicas utilizadas? Quais as concepções de trabalho docente predominantes? Quais os principais resultados apontados sobre o trabalho docente?

$\mathrm{Na}$ tentativa de responder os questionamentos supramencionados, foram selecionadas pesquisas realizadas no período delimitado pelas recentes reformas educacionais, 1996 a 2018, sendo o primeiro ano coincidente com a implantação da primeira reforma educacional de base gerencialista, e o segundo, com o término do levantamento bibliográfico que caracterizou a pesquisa.

Neste artigo, há a síntese dos resultados relativos ao processo de pesquisa pautado pela revisão bibliográfica realizada de forma quanti-qualitativa, buscando atender aos seguintes objetivos: a) analisar a produção acadêmica - teses e dissertações - sobre o trabalho docente no período de 19962018; b) identificar as etapas e as modalidades de ensino abordadas nas teses e dissertações; c) mapear os principais Programas de Pós-Graduação nos quais são produzidas as pesquisas; d) reconhecer as principais abordagens metodológicas presentes nas teses e dissertações; e) identificar as concepções de trabalho docente presentes nas produções acadêmicas; f) apresentar os principais eixos de análise das pesquisas produzidas no período.

\section{SITUANDO O OBJETO DE ESTUDO: O TRABALHO DOCENTE EM SÃO PAULO}

Com as transformações socioeconômicas ocorridas a partir da segunda metade do século XX e início do século XXI, o mundo do trabalho sofreu profundas alterações. De acordo com Souza (1999), em decorrência da crise estrutural capitalista, nos anos finais da década de 1960 e início da década 1970, provocada pelo aumento do preço do petróleo, o mundo presenciou a queda econômica dos maiores grupos ocidentais industrializados e a notável ampliação das desigualdades econômicas. A partir das transformações no mundo do trabalho assalariado, o capital criou novas estratégias visando superar a situação econômica que estava sendo vivida, dentre as quais, recorreu-se ao neoliberalismo e seus princípios básicos de promoção do Estado Mínimo, com pouca intervenção estatal, defesa da privatização dos serviços públicos e incentivo ao consumismo exacerbado (SOUZA, 1999).

Os pressupostos do neoliberalismo tiveram grande penetração em diferentes países do mundo em decorrência da atuação dos organismos internacionais que contribuíram para que estes se tornassem tendência hegemônica na economia e na organização da sociedade. A partir das experiências 
iniciais nos países desenvolvidos, o neoliberalismo avançou na América Latina, tendo suas primeiras investidas no Chile, na década de 1970. A partir dos anos 90, o neoliberalismo, sob o rótulo de Nova Gestão Pública, ganhou força e presença no Brasil com a eleição de Fernando Henrique Cardoso (19951998; 1999-2002) e a implantação da Reforma do Estado (BRASIL, 1995).

No caso da educação, os organismos internacionais, com destaque para o Banco Mundial, foram importantes veículos de disseminação dos pressupostos do neoliberalismo, já que, com frequência, emitiam notas técnicas e promoviam grandes eventos voltados aos representantes dos diferentes países, a exemplo da Conferência Mundial de Educação para Todos. Tais organismos tiveram grande influência nas decisões governamentais, como foi o caso do governo brasileiro, que incorporou muitas das prescrições em disposições legais que sustentaram as reformas no ensino. Com a justificativa de promover a equidade social, a transparência pública e a qualidade da educação, foram incorporados, às medidas implantadas, argumentos e práticas de cunho político e ideológico relativos ao neoliberalismo.

As políticas neoliberais tornaram-se tendência hegemônica no Brasil, num momento em que ainda era muito forte a luta pela garantia do acesso e permanência na escola e pela ampliação dos direitos sociais, marcas do Estado de bem-estar social que o Brasil nunca chegou a vivenciar. O neoliberalismo, dessa forma, contribuiu para o retrocesso nas políticas sociais, prezando pela estabilidade monetária em detrimento do gasto social (HYPOLITO, 2011). No âmbito das medidas que passaram a ser tomadas, ganharam força aquelas que introjetaram no serviço público a organização advinda do setor privado. Sendo assim, avançaram as práticas de natureza gerencial e performática que alteraram a organização escolar e a relação dos profissionais com o trabalho, mas que, por outro lado, não garantiram, em igual medida, as condições satisfatórias aos trabalhadores docentes.

A respeito do trabalho docente, partimos da premissa defendida por Duarte (2011) de que se trata de categoria analítica que possui especificidades e natureza próprias diante do processo marcado por contradições que a sociedade capitalista impõe. Desse modo, o contexto sociopolítico que permeia o trabalho docente desencadeia transformações para atender à lógica do capital. A essa premissa, incorporamos a definição de Oliveira (2004, p. 1132), que considera o trabalho docente não apenas "como atividade em sala de aula, ele agora compreende a gestão da escola no que se refere à dedicação dos professores ao planejamento, à elaboração de projetos, à discussão coletiva do currículo e da avaliação". A referida autora, em outra publicação, afirma que, embora os professores sejam os primeiros a serem lembrados quando se utiliza o termo trabalho docente, este é mais amplo e envolve todo ato de realização no processo educativo:

Trata-se de uma categoria que abarca tanto os sujeitos que atuam no processo educativo nas escolas e em outras instituições de ensino, nas suas diversas caracterizações de cargos, funções, tarefas, especialidades e responsabilidades, determinando suas experiências e identidades, quanto às atividades laborais realizadas. Compreende, portanto, as atividades e relações presentes nas instituições educativas, extrapolando a regência de classe (OLIVEIRA, 2010, P. 1).

Nesse sentido, o trabalho docente pode englobar ações educativas realizadas no âmbito do processo pedagógico em sala de aula, na relação direta com os estudantes, ou em outras tarefas vinculadas à docência, tais como participação em colegiados, realização de atividades burocráticas, atendimento à comunidade etc. Para além das atividades realizadas em sala de aula, há, também, aquelas que mantêm relação com a atividade educativa e que são desenvolvidas pelo professor no espaço educativo mais amplo, materializando-se nas ações do professor coordenador, coordenador pedagógico, diretor escolar, supervisor pedagógico, supervisor de ensino, entre outros. Para Marin e Bueno (2017), o termo trabalho docente - que “foi considerado por alguns como substitutivo para o 'não' uso da palavra didática - na verdade é mais amplo e abrangente, pois considera outros aspectos da função e muitas vezes nem o próprio ato de ensino" (p. 21).

O trabalho docente é complexo e "não consiste apenas em cumprir ou executar uma tarefa, mas é também a atividade de pessoas que não podem trabalhar sem dar um sentido ao que fazem [...]", é uma prática permeada pelo contexto no qual o trabalhador está inserido (TARDIF, 2005, p. 38). Dessa forma, o trabalho docente, especialmente a partir da década de 90, vivenciou um contexto de trabalho 
marcado pela intensificação das atividades, pela precarização, pela redução de custos expressa no arrocho salarial e pelas diversas modificações nos direitos dos trabalhadores e suas jornadas de trabalho (MARIN, 2010; BARBOSA et al., 2020). Além dessas condições objetivas que foram profundamente alteradas a partir das reformas, houve, conforme Barbosa e Fernandes (2016, p. 120), um forte processo de controle do trabalho e redução da autonomia, ampliando-se a regulação institucional por meio das avaliações externas, implantação de currículo centralizado e pagamento de bonificação.

Nos últimos anos, em função dos princípios da NGP e de suas implicações na organização do trabalho docente, essa categoria tornou-se objeto de amplos e variados estudos voltados à sua compreensão e contextualização, conforme apontados por Oliveira e Vieira (2012), Duarte (2011) e Mancebo (2007). Em consonância com tais estudos e perante a ausência de dados que sistematizassem a produção acadêmica sobre o trabalho docente no estado de São Paulo, buscamos organizar um quadro referência com um balanço das teses e dissertações publicadas ao longo de mais de duas décadas de reformas educacionais.

Em São Paulo, as reformas tomaram corpo a partir da eleição do Partido da Social Democracia Brasileira (PSDB), em 1995. Concomitantemente, Fernando Henrique Cardoso ocupou no mesmo ano o poder executivo do País, desenhando-se, então, uma oportunidade concreta para colocar em prática o Plano Diretor da Reforma do Aparelho do Estado, sob o mandato de Luiz Carlos Bresser Pereira, no Ministério da Administração Federal e Reforma do Estado (MARE). Em São Paulo, as palavras de ordem para a reforma do Estado foram "qualidade e produtividade" do serviço público, marcas da NGP. O PSDB, de acordo com Stocco e Jacomini (2020), passou a ser "o maior representante de uma elite paulista vinculada a uma visão de gestão modernizadora (técnico-racional) e, curiosamente, contrariando a denominação expressa no seu nome, o grupo mais organizado e articulado no projeto de um Estado Neoliberal".

De acordo com Venco (2016), o estado de São Paulo foi, nesse sentido, um laboratório social na aplicação e disseminação dos princípios da NGP, influenciando outros estados do País a adotarem medidas que aproximavam o serviço público do mercado, baseando-se em um estilo gerencial pautado pelo mérito e pela produtividade. Dessa forma, o PSDB - que segue no poder há mais de duas décadas ininterruptamente - levou a cabo uma série de medidas articuladas em todos os campos da administração pública. As medidas postas em prática tinham certo toque "inovador", aspecto logrado tanto pela repercussão positiva junto à população graças à retórica dos reformadores, como pela apropriação (indevida pela característica assumida) de bandeiras políticas dos movimentos em defesa da escola pública, tais como gestão democrática, valorização da escola como centro de formação docente, importância do trabalho coletivo e da autonomia (FERNANDES, 2010).

A partir desse momento, no qual medidas chegaram às escolas nos primeiros meses de 1996 até o programa "São Paulo faz Escola", iniciado em 2007 e vigente até 2018, ocorreram alterações consideráveis na organização e gestão pedagógica das escolas, na estrutura curricular e na composição da carreira e salários docentes. E, embora as reformas do período tenham sido anunciadas em nome de uma suposta "qualidade" da educação, expressas em preocupações oficiais com os resultados quantitativos coletados no desempenho das escolas nas avaliações externas, persistiram e se acumularam os problemas estruturais da educação pública voltada à ampla maioria da população (FERNANDES, 2018).

Tendo em tela esse contexto, buscamos identificar como as pesquisas - teses e dissertações - analisaram o trabalho docente no estado de São Paulo, no âmbito da série de reformas difundidas pelo governo entre 1996 a 2018.

\section{PERCURSO METODOLÓGICO}

Tomando-se como ponto de partida as questões e objetivos mencionados na introdução deste artigo, realizamos uma investigação de natureza quali-quantitativa para a qual adotamos a abordagem metodológica da pesquisa bibliográfica, a fim de buscar elementos necessários para mapear e analisar o objeto central de análise - trabalho docente - nas teses e dissertações produzidas nos principais programas de Pós-Graduação em Educação do estado de São Paulo, no período de 1996 a 
2018. A revisão bibliográfica foi a abordagem mais adequada por ser aquela que, segundo Mazzotti (1998), permite conhecer a produção num determinado campo, propiciando avanços frente a novos estudos.

Assim, durante o processo de levantamento das pesquisas já produzidas sobre o objeto de análise, ficou evidente a necessidade de um estudo que agrupasse e analisasse o conjunto das produções acadêmicas sobre o trabalho docente no estado de São Paulo, proporcionado pela revisão bibliográfica. Morosini e Fernandes (2014) apontam que a revisão permite o mapeamento de concepções existentes, promovendo ao pesquisador uma segurança com relação às fontes utilizadas e indicando um aprofundamento sobre o tema de estudo. Marin e Bueno (2017) também ressaltam a importância das revisões de pesquisas:

Espera-se que revisões de pesquisas, nas diversas áreas do conhecimento, apresentem visão ampla tanto dos temas quanto das formas de abordagem teórica e metodológica atribuindo, portanto, relevância a tal tipo de estudo. No campo educacional, os estudos dessa natureza podem fornecer conjuntos integrados e interpretações amplas das pesquisas em diferentes focos. (MARIN E BUENO, 2017, P. 18)

Dessa maneira, a pesquisa, apesar de apresentar um recorte específico de espaço e tempo, pretendeu contribuir com novas produções acadêmicas e nortear outros estudos, seja nesta ou nas demais regiões do País.

Para o levantamento dos dados bibliográficos, foram utilizados os seguintes descritores combinados: Política Educacional, Reforma Educacional; Trabalho Docente e estado de São Paulo. Os dados foram obtidos nos repositórios digitais dos principais Programas de Pós-Graduação em Educação do estado de São Paulo: Universidade Estadual de Campinas (Unicamp); Universidade Federal de São Paulo (Unifesp); Universidade Federal de São Carlos (Ufscar); Universidade Estadual Paulista "Júlio de Mesquita Filho" (Unesp); Universidade de São Paulo (USP); Universidade Metodista de Piracicaba (Unimep); Universidade Metodista de São Paulo (Umesp), Pontifícia Universidade Católica de Campinas (Puccamp) e Pontifícia Universidade Católica de São Paulo (PUCSP). Foram abrangidas no levantamento nove instituições, nas quais foram contabilizados 14 Programas de Pós-Graduação, em função de algumas IES terem mais de um Programa em Educação, caso da USP, Unesp, Ufscar e PUCSP.

O levantamento em sua fase inicial considerou três critérios principais de seleção da produção acadêmica: a) recorte temporal delimitado pelo início das reformas educacionais do estado em São Paulo (1996); b) estudos realizados sobre o sistema regular de ensino da rede estadual paulista de ensino, já que as reformas educacionais em tela definiram normas, regras e ritos para este grupo específico de escolas; c) pesquisas sobre trabalho docente nas etapas de ensino sob a responsabilidade do governo estadual - Ensino Fundamental (anos iniciais e anos finais) e Ensino Médio. Por conseguinte, outros níveis, modalidades de ensino e formas de educação não foram contemplados, dentre eles: educação infantil, educação superior, educação no campo, educação no sistema prisional, educação informal. Sendo assim, o montante de trabalhos (2.930) foi reduzido, após leitura dos resumos e em atendimento aos critérios estabelecidos, a 134 trabalhos, os quais foram lidos e analisados na íntegra.

Para a leitura, numa primeira fase, foi utilizado o software Alceste, que nos permitiu analisar a frequência das palavras e conceitos presentes nas pesquisas. O uso deste recurso tecnológico na pesquisa foi importante pelas possibilidades oferecidas para a captação de dados quantitativos; mas, também, como parte do processo do levantamento, foi necessário reconhecer as limitações que apresentava para a pesquisa qualitativa. Diante deste fato, quando o software não se mostrou mais viável para a obtenção de dados analíticos, recorremos à leitura integral dos textos, registrando os dados obtidos em tabelas Excel.

A partir do conjunto de dados obtidos nas duas fases supracitadas, iniciamos o processo de análise e categorização de dados que se deu em função de teorizações progressivas com os principais autores de referência da pesquisa - Ball (2005), Oliveira e Vieira (2012), Oliveira (2004; 2010), Mancebo (2007), Duarte (2008 ; 2011), Marin (2010), Fernandes (2009; 2016; 2018). O conjunto foi organizado a partir de unidades temáticas, que serão apresentadas na próxima seção. 


\section{AS PRODUÇÕES ACADÊMICAS SOBRE TRABALHO DOCENTE NO ESTADO DE SÃO PAULO: ANÁLISE DOS DADOS}

A partir do levantamento de informações das 134 pesquisas selecionadas, foi possível apresentar alguns dados objetivos relativos à etapa de Pós-Graduação (mestrado e doutorado). No conjunto, foram selecionadas 111 dissertações de mestrado, representando aproximadamente $83 \%$, e 23 teses de doutorado, que equivalem a 17\% do total. É importante também destacar a quantidade total de trabalhos produzidos de acordo com a Instituição de Ensino Superior em que os Programas estão inseridos:

Quadro 1 - Produção acadêmica dos trabalhos selecionados distribuídos por IES

\begin{tabular}{|c|c|c|c|}
\hline \multicolumn{4}{|c|}{ Produção acadêmica dos trabalhos selecionados } \\
\hline Instituição & $\begin{array}{c}\text { Número de } \\
\text { Teses }\end{array}$ & $\begin{array}{c}\text { Número de } \\
\text { Dissertações }\end{array}$ & $\begin{array}{c}\text { Total produção } \\
\text { acadêmica }\end{array}$ \\
\hline Unesp & 9 & 44 & 53 \\
\hline Unicamp & 7 & 12 & 19 \\
\hline USP & 4 & 9 & 13 \\
\hline PUCSP & 2 & 11 & 13 \\
\hline Unifesp & - & 10 & 10 \\
\hline Unimep & - & 10 & 6 \\
\hline Puccamp & - & 6 & 6 \\
\hline Ufscar & 1 & 5 & 4 \\
\hline Umesp & - & 4 & $\mathbf{1 3 4}$ \\
\hline TOTAL & $\mathbf{2 3}$ & $\mathbf{1 1 1}$ & \\
\hline
\end{tabular}

Fonte: Elaborado pelos autores.

A IES com maior número de teses e dissertações sobre Trabalho Docente foi a Universidade Estadual Paulista (Unesp), totalizando 53 trabalhos (aproximadamente 40\%), produzidos em quatro diferentes Programas de Pós-Graduação, situados nos campus universitários de Araraquara (17 pesquisas), Rio Claro (13 pesquisas), Presidente Prudente (12 pesquisas) e Marília (11 pesquisas). A referida instituição tem uma característica multicampi, e, na unidade universitária onde identificamos a maior produção, Araraquara, foi localizado um dos primeiros Grupos de Estudos sobre Trabalho Docente no Brasil. Na sequência, destacou-se a Unicamp com 14\% da produção, seguida pela USP e PUCSP, com respectivamente 10\% das teses e dissertações. As demais IES - Unifesp, Puccamp, Unimep, Ufscar e Umesp - corresponderam conjuntamente a aproximadamente $27 \%$ da produção acadêmica.

Ao fazer a correspondência entre os Programas de Pós-Graduação e as linhas de pesquisas nas quais as teses e dissertações se encontravam distribuídas (Quadro 2), verificamos concentração em algumas linhas específicas que se voltam à análise do trabalho docente; inclusive, em algumas, o conceito aparece na própria denominação, caso da Unesp, Unicamp e Unimep. Em outros casos, o trabalho docente foi objeto de análise em linhas voltadas à discussão das políticas educacionais e gestão; formação de professores; análise da instituição escolar e relações entre estado, sociedade e educação. Tais linhas são representativas e coerentes com o conceito de trabalho docente, como atividade humana imersa numa sociedade contraditória.

Quadro 2-Linhas de pesquisa e Programas a que estão relacionadas as pesquisas

\begin{tabular}{|c|c|c|c|}
\hline \multirow{2}{*}{ IES } & $\begin{array}{c}\text { Programa de Pós- } \\
\text { Graduação }\end{array}$ & Linhas de Pesquisa & $\begin{array}{c}\text { Total de trabalhos } \\
\text { por linha }\end{array}$ \\
\hline \multirow{2}{*}{ Unesp } & $\begin{array}{c}\text { Educação Escolar } \\
\text { (Araraquara) }\end{array}$ & $\begin{array}{c}\text { Formação do Professor, Trabalho } \\
\text { Docente e Práticas Pedagógicas }\end{array}$ & 9 \\
\cline { 3 - 4 } & & Teorias Pedagógicas, Trabalho Educativo & 3 \\
\cline { 3 - 4 } & & e Sociedade & 5 \\
\cline { 3 - 4 } & & Política e Gestão Educacional & 3 \\
\hline
\end{tabular}




\begin{tabular}{|c|c|c|c|}
\hline & \multirow[t]{2}{*}{ Educação (Rio Claro) } & $\begin{array}{l}\text { Educação: políticas, gestão e o sujeito } \\
\text { contemporâneo }\end{array}$ & 10 \\
\hline & & $\begin{array}{l}\text { Formação de Professores e Trabalho } \\
\text { Docente }\end{array}$ & 3 \\
\hline & \multirow[t]{2}{*}{$\begin{array}{l}\text { Educação (Presidente } \\
\text { Prudente) }\end{array}$} & $\begin{array}{l}\text { Processos Formativos, Infância e } \\
\text { Juventude }\end{array}$ & 1 \\
\hline & & $\begin{array}{l}\text { Formação dos Profissionais da Educação, } \\
\text { Políticas Educativas e Escola Pública }\end{array}$ & 11 \\
\hline & Educação (Marília) & $\begin{array}{c}\text { Políticas Educacionais, Gestão de Sistemas } \\
\text { e Organizações, Trabalho e Movimentos } \\
\text { Sociais }\end{array}$ & 11 \\
\hline \multicolumn{2}{|c|}{ Subtotal } & \multicolumn{2}{|l|}{53} \\
\hline \multirow[t]{8}{*}{ Unicamp } & \multirow[t]{8}{*}{ Educação } & Educação e Ciências Sociais & 6 \\
\hline & & Educação e História Cultural & 1 \\
\hline & & $\begin{array}{c}\text { Educação em Ciências, Matemática e } \\
\text { Tecnologias }\end{array}$ & 1 \\
\hline & & Estado, Políticas Públicas e Educação & 4 \\
\hline & & Filosofia e História da Educação & 2 \\
\hline & & $\begin{array}{l}\text { Formação de Professores e Trabalho } \\
\text { Docente }\end{array}$ & 3 \\
\hline & & Linguagem e Arte em Educação & 1 \\
\hline & & Psicologia e Educação & 1 \\
\hline \multicolumn{2}{|c|}{ Subtotal } & \multicolumn{2}{|l|}{19} \\
\hline \multirow[t]{3}{*}{ PUCSP } & Educação: Currículo & $\begin{array}{l}\text { Políticas Públicas e Reformas } \\
\text { Educacionais e Curriculares }\end{array}$ & 2 \\
\hline & \multirow[t]{2}{*}{$\begin{array}{l}\text { Educação: História, } \\
\text { Política e Sociedade }\end{array}$} & $\begin{array}{l}\text { Teoria Crítica da Sociedade e Formação - } \\
\text { Função Social da Educação e da Escola }\end{array}$ & 3 \\
\hline & & $\begin{array}{l}\text { Instituição Escolar: Organização, Práticas } \\
\text { Pedagógicas e Formação de Educadores }\end{array}$ & 8 \\
\hline \multicolumn{2}{|c|}{ Subtotal } & \multicolumn{2}{|l|}{13} \\
\hline \multirow[t]{4}{*}{ USP } & \multirow[t]{4}{*}{ Educação } & Cultura, Filosofia e História da Educação & 1 \\
\hline & & $\begin{array}{c}\text { Educação e Ciências Sociais: } \\
\text { Desigualdades e Diferenças }\end{array}$ & 1 \\
\hline & & Estado, Sociedade e Educação & 9 \\
\hline & & $\begin{array}{l}\text { Formação, Currículo e Práticas } \\
\text { Pedagógicas }\end{array}$ & 2 \\
\hline \multicolumn{2}{|r|}{ Subtotal } & \multicolumn{2}{|l|}{13} \\
\hline \multirow[t]{2}{*}{ Unifesp } & \multirow[t]{2}{*}{ Educação } & Educação, Estado, Trabalho & 7 \\
\hline & & $\begin{array}{c}\text { Escola Pública, Formação de Professores } \\
\text { e Práticas Pedagógicas }\end{array}$ & 3 \\
\hline \multicolumn{2}{|c|}{ Subtotal } & \multicolumn{2}{|l|}{10} \\
\hline \multirow[t]{2}{*}{ Unimep } & \multirow[t]{2}{*}{ Educação } & História e Filosofia da Educação & 1 \\
\hline & & $\begin{array}{l}\text { Trabalho Docente, Formação de } \\
\text { Professores e Políticas Educacionais }\end{array}$ & 9 \\
\hline \multicolumn{2}{|c|}{ Subtotal } & \multicolumn{2}{|l|}{$\begin{array}{ll}10 \\
\end{array}$} \\
\hline \multirow[t]{2}{*}{ Puccamp } & \multirow[t]{2}{*}{ Educação } & $\begin{array}{c}\text { Formação de Professores e Práticas } \\
\text { Pedagógicas }\end{array}$ & 4 \\
\hline & & Políticas Públicas em Educação & 2 \\
\hline \multicolumn{2}{|r|}{ Subtotal } & $\begin{array}{r} \\
\end{array}$ & \\
\hline Ufscar & Educação & Educação Escolar: Teorias e Práticas & 2 \\
\hline & & Educação, Cultura e Subjetividade & 1 \\
\hline & & Estado, Política e Formação Humana & 2 \\
\hline & & $\begin{array}{c}\text { Formação de Professores e outros Agentes } \\
\text { Educacionais }\end{array}$ & 1 \\
\hline & ubtotal & $\begin{array}{l} \\
\end{array}$ & \\
\hline Umesp & Educação & Políticas e Gestão Educacionais & 2 \\
\hline & & Formação de Educadores & 2 \\
\hline & ubtotal & 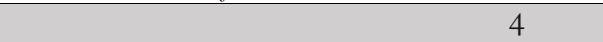 & \\
\hline
\end{tabular}

Fonte: Elaborado pelos autores. 
Ao enfatizar o ano de publicação das pesquisas, observamos uma recorrência em determinados intervalos dentro do recorte temporal estabelecido - 1996 a 2018 -, como sintetizado no gráfico a seguir:

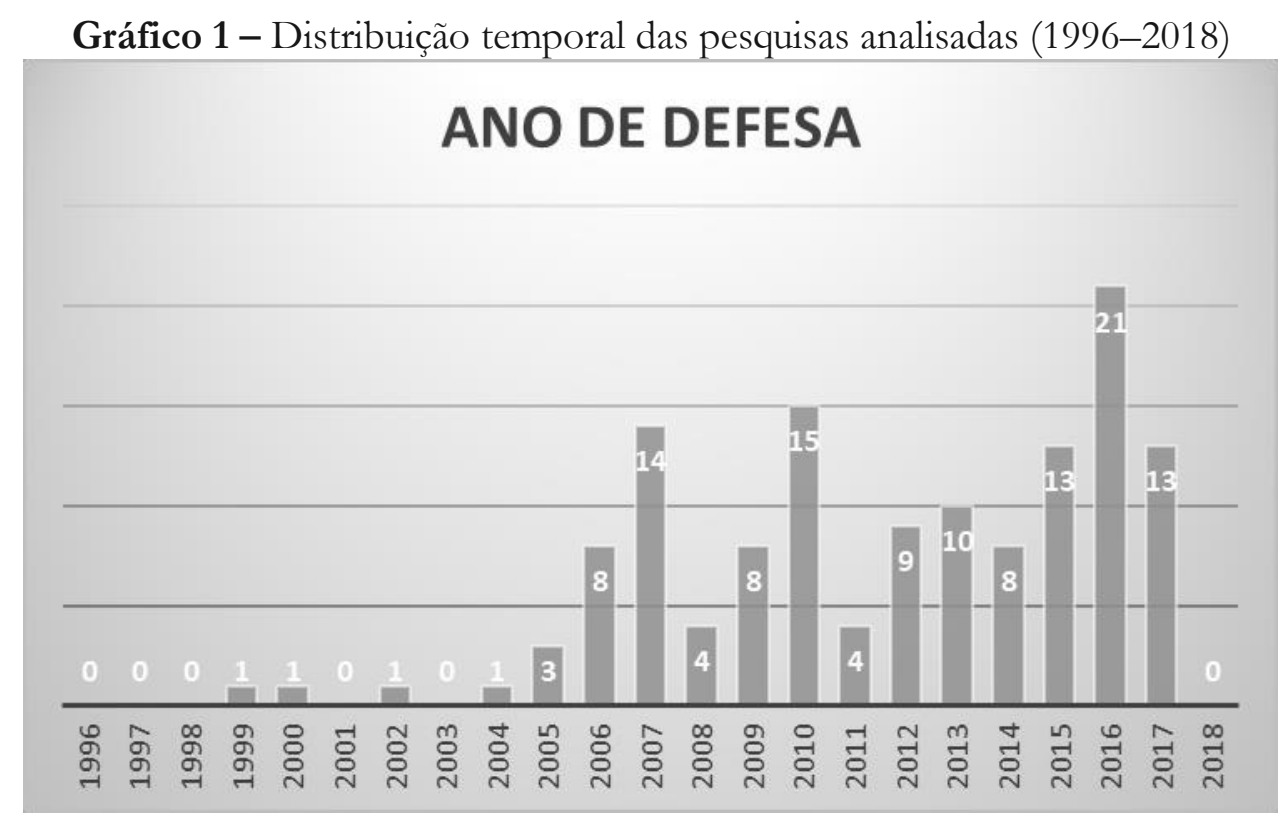

Fonte: Elaborado pelos autores.

O conjunto de pesquisas tem seu primeiro registro a partir de 1999, quatro anos após a ocorrência das primeiras medidas educacionais - reorganização física das escolas, implantação da progressão continuada, criação do sistema de avaliação - baseadas na Nova Gestão Pública. É provável que a ausência de pesquisas sobre trabalho docente no período de 1996 a 1998 esteja relacionada ao intervalo de tempo entre a implantação e a implementação da política educacional, já que é necessário um tempo entre a elaboração e efetivação da reforma e a apropriação desta pelo espaço escolar, de forma positiva ou negativa, para depois se transformar em objeto de análise pelas pesquisas. A partir de 2004, observou-se um crescimento contínuo das pesquisas, sendo que os anos de 2007, 2010, 2015 e 2017 apresentaram número de publicações superior a dez, com crescimento que se destacou em relação a períodos anteriores. O ponto alto da produção ficou por conta do ano de 2016, vinte anos após a reforma inicial intitulada "Escola de Cara Nova", com 21 pesquisas (teses e dissertações). Em 2020, completouse também uma década do Programa São Paulo faz escola, o qual, diante das reformas anteriores, aprofundou as medidas de caráter gerencial na rede de ensino (FERNANDES, 2018; STOCCO e JACOMINI, 2020).

Os trabalhos defendidos neste período ${ }^{3}$ abordaram as medidas e as mudanças decorrentes das mesmas no trabalho docente, seja por meio da análise: a) da implantação de projetos e programas (LEME, 2007; OLIVEIRA, 2007; FERREIRA, 2009; BRENDANT, 2010; RODRIGUES, 2010; ALMEIDA, 2014; IGNÁCIO, 2014; MIGUEL, 2015; TORRES, 2016); b) da implantação e implementação do currículo padronizado (LEITE, 2011; GIAVARA, 2012; OLIVEIRA, 2012; MARQUES, 2014; NUNES, 2014; FERIN, 2015); c) das avaliações externas (CHIRINEA, 2010; NALLO, 2010; OLIVEIRA JR, 2013; JESUS, 2014; POLATO, 2014; COLOMBO, 2015; MARTINS, 2015; PARRO, 2016; PERBONI, 2016; RUBINI, 2016; FILIPE, 2017; GREVE, 2017); d) da redução da autonomia docente (NOTARIO, 2007; VIÇOTI, 2010; FREITAS, 2014; FILGUEIRA, 2017); e) da política de bonificação por resultados (VASCONCELOS, 2006; ALCANTARA, 2010; BERGO, 2016);

\footnotetext{
${ }^{3}$ Não serão apresentadas textualmente neste artigo todas as pesquisas que compuseram o conjunto de análise, destacando-se, a título de ilustração, apenas algumas das produções analisadas.
} 
f) da implantação de mecanismos de privatização na rede estadual (CARVALHO, 2016; PARENTE, 2016; OLIVEIRA, 2017).

Encontramos, ainda, pesquisas que se dispuseram a analisar os ciclos de reformas promovidas no estado pelo PSDB (SOUZA, 1999; VILELA, 2002; NUNES, 2005; MOREIRA, 2007; MATTOOS, 2012; LIMA, 2015; JARDIM, 2016), as alterações na função da escola (RAAB, 2016) ou os desafios impostos pelas reformas (PIOLLI, 2006). A produção de pesquisas voltadas à análise das condições de trabalho docente no estado de São Paulo também foram identificadas, dentre as quais se destacaram as realizadas por Aquino (2009), Aranha (2007), Oliveira (2010), Barbosa (2011), Merguedicthian (2012), Basílio, (2016), Cassetari (2010), Catini (2008), Santos (2016a,) e Santos (2016b). Entretanto, apenas duas dissertações se propuseram a analisar o movimento sindical no contexto de reformas (LANZA, 2010; HIDAKA, 2012; SILVA, 2013). Ao organizarmos a produção acadêmica em função dos anos e focos de pesquisa, inferimos que a produção acadêmica sobre trabalho docente ganhou fôlego e ampliou seus focos de investigação à medida que se ampliaram as reformas gerenciais na educação paulista, dado que se aproximou do citado por Mancebo (2007) sobre o crescimento das pesquisas no País.

Quanto à abordagem metodológica, identificamos um predomínio, dentre as teses e dissertações, da pesquisa qualitativa, presente em 128 trabalhos, correspondendo a mais de 95\% da produção acadêmica. Foram identificados seis trabalhos de abordagem quali-quantitativa. Contudo, nenhuma pesquisa se configurou exclusivamente na abordagem quantitativa. Este é um dado importante e que carece ser discutido nas redes de estudos sobre trabalho docente, pois reflete, de maneira geral, a forma como olhamos e analisamos as questões relativas ao trabalho, partindo de aspectos micros que vão sendo interpretados baseados na relação com o contexto macrossocial. Normalmente, analisamos o trabalho docente, e os dados são uma mostra disso, a partir de uma escola ou um grupo reduzido de instituições, um docente ou um conjunto de professores. O denominado paradigma qualitativo, segundo Alves-Mazzotti e Gewandsznadjer (2002), avançou no Brasil desde a década de 1980, seguindo a tradição interpretativa, que valoriza o sentido e o significado que fatos ou comportamentos podem ter e que não podem ser desvelados de imediato, necessitando de um trabalho de investigação marcado por um contato mais direto e prolongado entre o pesquisador e o objeto de análise.

Não pretendemos fazer aqui nenhuma oposição entre a pesquisa qualitativa e a quantitativa, estabelecendo juízos de valor, mas, apenas, trazer elementos para refletirmos, a partir dos "achados" da revisão bibliográfica, a necessidade de discutirmos a realização de investigações temáticas com universos maiores, de natureza interinstitucional e de abordagem quanti-qualitativa, que possam se contrapor aos surveys que são realizados, muitas vezes, por institutos ligados à área econômica e administrativoempresarial e que servem de argumentos para a tomada de decisões acerca da educação escolar.

A análise da produção acadêmica selecionada também indicou uma frequência maior das pesquisas empíricas (95 trabalhos, correspondentes a 71\%), seguidas pelas bibliográfico-documentais, documentais e/ou bibliográficas (39 trabalhos, 29\%). As entrevistas foram predominantes entre as possibilidades de coleta de dados, aparecendo em 75 pesquisas ( $79 \%$ dentre as pesquisas empíricas), seguidas pelos estudos de caso (15 investigações), pelo uso de questionários abertos e/ou fechados (22 pesquisas), depoimentos e realização de grupos focais (que somaram 5 pesquisas). Importante registrar que diversas pesquisas utilizaram diferentes procedimentos e instrumentos de coleta, não se limitando a uma única fonte, daí a somatória ser superior ao número obtido no conjunto das pesquisas empíricas. No entanto, a grande maioria ainda faz uso de apenas um instrumento de coleta de dados.

Dentre os participantes das pesquisas empíricas destacaram-se os professores que foram sujeitos únicos em 47 trabalhos, número que se aproxima de 50\% das investigações. Entretanto, quando contabilizadas as teses e dissertações cujo foco foi o trabalho do professor junto com outros profissionais que se dedicam ao trabalho pedagógico (professor coordenador, diretor, dirigente etc.), o número obtido foi de 86 pesquisas, sendo o professor, nesta situação, o maior destaque dentre os participantes das pesquisas $(90 \%)$. Dessa forma, observamos que o trabalho desenvolvido em sala de aula pelos trabalhadores docentes se constitui, no estado de São Paulo, na base principal de participação e estudo nas pesquisas realizadas, indicando que o trabalho docente, enquanto categoria analítica, ainda fica muito restrito ao "trabalho do professor". 
Observando mais detalhadamente os participantes nos processos de coleta de dados, identificamos a presença de: professor e professor coordenador (10 pesquisas); professor e gestor (13 pesquisas); professor, professor coordenador e gestor (16 pesquisas). Os professores coordenadores (PC), denominação atribuída pela Secretaria de Educação de São Paulo (SEDUC) aos coordenadores pedagógicos, foram participantes exclusivos em apenas uma pesquisa empírica. Porém, ao combinar os participantes pesquisados, o resultado é de 29 pesquisas com o PC. Os gestores, por sua vez, quando combinados aos demais sujeitos participantes, abarcaram 32 pesquisas. Os supervisores e dirigentes de ensino, que na estrutura da SEDUC atuam nos órgãos intermediários de gestão, denominados de Diretorias de Ensino, foram participantes de sete pesquisas. Embora os professores sejam os mais privilegiados na coleta de dados, o que pode indicar que o termo trabalho docente seja utilizado no sentido restrito de prática pedagógica, identificou-se que a concepção ampliada e extensiva a outros profissionais da educação também é evidente na produção acadêmica.

Outra unidade analítica voltou-se à identificação da etapa e modalidade de ensino abordada nas teses e dissertações de base empírica. As pesquisas de tipo bibliográfico-documental não foram incluídas no Quadro 3 (a seguir), porque não direcionavam o foco especificamente para as etapas e modalidades de ensino nas quais o trabalho docente era realizado, dedicando-se estas pesquisas à análise de questões mais amplas e relacionadas à implantação de políticas educacionais de maneira geral, como por exemplo: "Políticas de bonificação e indicadores de qualidade: mecanismos de controle nas escolas estaduais paulistas" (ALCANTARA, 2010); "Os salários dos professores brasileiros: implicações para o Trabalho Docente" (BARBOSA, 2011); e "Profissionalização docente e subordinação do trabalho educativo à lógica flexível da produção capitalista” (CARVALHO, 2016).

Dessa maneira, consideramos no Quadro 3 apenas as 95 pesquisas que se dirigiram indubitavelmente a uma determinada etapa e modalidade de ensino:

Quadro 3 - Total de trabalhos por Etapa de Ensino e modalidade de ensino

\begin{tabular}{|l|c|}
\hline \multicolumn{1}{|c|}{ Etapa de Ensino } & Total de Trabalhos \\
\hline $\begin{array}{l}\text { Ensino Fundamental I } \\
\left(\text { Anos Iniciais }-1^{\circ} \text { ao } 5^{\circ} \text { ano }\right)\end{array}$ & 17 \\
\hline Ensino Fundamental II (Anos Finais $-6^{\circ}$ ao $9^{\circ}$ ano) & 9 \\
\hline Ensino Médio & 9 \\
\hline Ensino Fundamental I e II $\left(1^{\circ}\right.$ ao $9^{\circ}$ ano) & 19 \\
\hline Ensino Fundamental I, II e Ensino Médio & 23 \\
\hline Ensino Fundamental II e Ensino Médio & 18 \\
\hline Total de Trabalhos & $\mathbf{9 5}$ \\
\hline
\end{tabular}

Fonte: Elaborado pelos autores a partir dos dados das pesquisas.

A totalidade do conjunto sistematizado no Quadro 3 voltou-se à análise do ensino regular oferecido pela rede estadual paulista. Ao se tomar como foco as etapas de ensino, verificou-se que, quando tomada apenas uma etapa como unidade de análise, o predomínio das pesquisas foi sobre o Ensino Fundamental: anos iniciais $-1^{\circ}$ ao $5^{\circ}$ ano (17 trabalhos, representando $18 \%$ da produção empírica) - e anos finais ( 9 pesquisas, $9 \%$ das pesquisas). Somando-se estes dois indicadores com aqueles apresentados pelo conjunto das pesquisas que considerou mais de uma etapa de escolaridade ( por exemplo, Ensino Fundamental I e II juntos), como unidade de análise, chegou-se ao número expressivo de aproximadamente $50 \%$ das pesquisas que tinham como foco o Ensino Fundamental. Este dado corrobora o apresentado por outras pesquisas de revisão, que, porém, com focos diferentes de investigação, indicaram ser esta etapa de escolaridade que vai do $1^{\circ}$ ao $9^{\circ}$ a principal preocupação dos pesquisadores, tendo em vista não apenas o volume de estudantes matriculados, mas, também, as características problemáticas do Ensino Fundamental (MARIN E BUENO, P 2018, P. 52). É importante também registrar que o percentual de pesquisas é alto mesmo tendo o Ensino Fundamental, anos iniciais, no estado de São Paulo, passado por intenso processo de municipalização ao longo da década de 1990 (BORGHI, 2007), coincidindo com a reforma do Estado. Já o Ensino Médio, atual gargalo do ensino no País e no estado, representou, isoladamente, apenas $9 \%$ das pesquisas realizadas. 
Com relação à base teórica mais adotada nas teses e dissertações, a partir do indicado nos resumos, identificamos que apenas 46 delas (34\%) apresentavam explicitamente a opção dos pesquisadores. De forma geral, foi possível inferir, pela forma como a análise era realizada e os dados interpretados, a direção teórica adotada. Porém, optamos, em relação a esta categoria, por nos pautarmos pela declaração irrestrita feita pelos autores das pesquisas. Nesse sentido, 20 trabalhos vincularam diretamente a base teórica dos estudos ao Materialismo Histórico Dialético, e três outras pesquisas o fizeram de forma indireta, citando apenas se tratar de pesquisa apoiada na Pedagogia Histórico-Crítica ou em Karel Kosik; assim, a referida base teórica foi a mais indicada pelos autores, correspondendo a $50 \%$ do grupo analisado, o qual havia declarado a base teórica adotada. Tal dado é seguido pela indicação do paradigma Weberiano presente em oito teses e dissertações (17\%); da Teoria Crítica e seus representantes - Adorno, Horkheimer e Marcuse (5 pesquisas, 11\%); da perspectiva sociológica de Pierre Bourdieu (11\%); dos estudos de Norbert Elias (4\%) e de François Dubet (2\%). De maneira geral, denotou-se a preocupação dos pesquisadores em analisar as especificidades do trabalho docente a partir de suas relações com a sociedade capitalista.

Para além da base teórica apresentada nos estudos selecionados, levantamos os autores estrangeiros e brasileiros mais citados, considerando-se aí as 134 teses e dissertações. Dentre os principais autores estrangeiros, identificamos: Stephen Ball, Mariano Fernandéz Enguita, Michael Apple e Almerindo Janela Afonso. Já entre os autores brasileiros, destacaram-se em ordem de citação: Dalila Andrade Oliveira, Luiz Carlos de Freitas, Dermeval Saviani, Gaudêncio Frigotto, Giovanni Alves, Ricardo Antunes e Alda Junqueira Marin. Este conjunto de pesquisadores da área da Educação e da Sociologia do Trabalho, tanto nacional como internacionalmente, pode ser considerado de autores críticos que apresentaram, nas últimas décadas, grandes contribuições para a compreensão do trabalho docente no âmbito das transformações políticas e sociais que têm efeitos sobre a atuação profissional nas escolas. São, portanto, autores que permitem estabelecer relações entre o nível macro e o micro escolar, favorecendo a identificação e a compreensão dos mecanismos impostos na cultura escolar e seus reflexos nas situações de redução da autonomia, de intensificação do trabalho e de flexibilização contratual, que por sua vez acarreta um processo de descaracterização das condições de trabalho e perda de identidade da categoria docente.

O quadro formado pelos autores centrais de referência e os apontamentos apresentados nas pesquisas, bem como os dados relativos ao tipo de investigação realizada, formas de coleta de dados e procedimentos, ajudaram a identifcar e compreender a concepção de trabalho docente presente na produção acadêmica selecionada, destacando-se: uma perspectiva de trabalho docente que vai além da sala de aula, embora com algumas pesquisas que utilizem o termo como sinônimo de prática docente, prática pedagógica ou didática; o trabalho docente como atividade complexa e submetida às contradições de uma sociedade capitalista e em transformação; a complexidade de um trabalho que não se reduz somente à sala de aula (mesmo quando o sujeito de análise era o professor), abarcando outras funções e atividades ligadas ao processo educativo; um trabalho marcado por especificidade e natureza própria que o diferencia (tanto pelo processo como pelos resultados) de outras ocupações laborais na sociedade; uma atividade que sofreu intensas alterações a partir das mudanças ocorridas no mundo do trabalho que introduziram no setor público mecanismos e estratégias advindas do setor privado-empresarial. Dessa forma, há grandes aproximações ao conceito de trabalho docente apresentado por Hypólito (1991), Oliveira (2010) e Duarte (2011).

O conjunto formado por 134 pesquisas, produzidas no intervalo entre os anos de 1996 a 2018, nos principais Programas de Pós-Graduação em Educação do estado de São Paulo, quando submetido a levantamento de frequência de descritores com apoio inicial de recurso tecnológico e, posteriormente, com leitura, categorização e análise manual de dados, permitiu-nos chegar a três grandes eixos analíticos que foram subdivididos, em função de ordem de ocorrência, em 13 subeixos a eles relacionados, como sintetizado no Quadro 4.

Quadro 4 - Eixos e subeixos de análise a partir da frequência de descritores Eixos de Análise Subeixos de Análise 


\begin{tabular}{|c|c|}
\hline \multirow{5}{*}{$\begin{array}{l}\text { Contexto abordado pelas pesquisas ao situar o(s) } \\
\text { objeto(s) de pesquisa }\end{array}$} & 1.2 Organismos internacionais \\
\hline & 1.3 Neoliberalismo \\
\hline & 1.4 Gerencialismo \\
\hline & 1.5 Performatividade \\
\hline & 1.6 Nova Gestão Pública (NGP) \\
\hline \multirow{4}{*}{$\begin{array}{c}\text { Eixo } 2 \\
\text { Características do Trabalho Docente }\end{array}$} & 2.1 Precarização \\
\hline & 2.2 Flexibilização \\
\hline & 2.3 Intensificação \\
\hline & 2.4 Proletarização \\
\hline \multirow{3}{*}{$\begin{array}{c}\text { Eixo } 3 \\
\text { Medidas reformistas }\end{array}$} & 3.1 Regulação \\
\hline & 3.2 Bonificação \\
\hline & 3.3 Avaliações Externas \\
\hline
\end{tabular}

Fonte: Elaborado pelos autores a partir dos dados das pesquisas analisadas.

$\mathrm{Na}$ grande maioria das pesquisas (128 delas), partiu-se da contextualização (Eixo 1) do trabalho docente a partir do sistema capitalista (subeixo 1.1), relacionando o tema central às questões conjunturais que o afetam, positiva e negativamente. Assim como adiantado por Hypólito, em artigo de 1991, “o processo de trabalho escolar está sendo penetrado por uma lógica capitalista e o modelo de organização vigente tende, mesmo que com novas conformações, a ser generalizável e dominante em nossa sociedade" (p.10). Assim, as pesquisas sobre trabalho docente, com suas características e especificidades, tornaram-se numericamente mais presentes na produção acadêmica, colocando em tela a forte presença do neoliberalismo (subeixo 1.2) como uma nova roupagem do capital que redefine o papel ao Estado. Nesse sentido, o neoliberalismo apareceu de forma recorrente em 112 trabalhos, dentre os quais se destacaram as pesquisas realizadas por Oliveira (2017); Carvalho (2010); Furtado (2005) e Regalo (2013). A Nova Gestão Pública (subeixo 6), configuração atual do neoliberalismo na transposição do modelo administrativo empresarial para a educação, foi nominalmente citada em oito pesquisas.

A referência à atuação dos organismos internacionais (subeixo 1.3) foi apresentada em 120 das teses e dissertações, das quais a principal citação é feita ao Banco Mundial e aos instrumentos que este criou e disseminou, influenciando as políticas estabelecidas e implantadas na educação paulista ao longo dos anos, como foi o caso das investigações realizadas por Antonini (2007); Carvalho (2010); Moreira (2007); Pinheiro (2010) e Viçoti (2010). Ainda com relação à caracterização do contexto no qual se situa o trabalho na educação paulista, identificamos a correlação entre o gerencialismo e a performatividade, denominadas por Ball como "duas das principais tecnologias da reforma educacional que envolve a utilização calculada de técnicas e artefatos para organizar forças humanas e capacidades em redes de poder" (2005, p. 543) e as condições de trabalho que incidem, por exemplo, em maior intensificação docente, flexibilização contratual e alterações na organização pedagógica do trabalho. O gerencialismo (subeixo 4) foi conceito abordado em 82 pesquisas, enquanto que a performatividade (subeixo 5), tecnologia que normalmente a ele está associada, apresentou frequência em 39 das produções, destacando-se, neste caso, as pesquisas que analisaram o impacto das avaliações externas no trabalho docente, bem como a padronização curricular e o pagamento de bonificação por desempenho, com destaque para as pesquisas realizadas por Rodrigues (2010); Cassetari (2010); Sousa (2016); Lanza (2016) e Parente (2016).

Quando agrupadas as pesquisas que tiveram como foco central de análise as características do trabalho docente (Eixo 2), reconhecemos tanto aquelas que se voltaram à discussão da especificidade desta atividade, caso de Aranha (2007); Penna (2007) e Barbosa (2011), que destacaram a complexidade de um trabalho remunerado insatisfatoriamente em função das exigências que carrega, como aquelas teses e dissertações que focalizaram a precarização, a intensificação, a flexibilização e a proletarização.

A precarização do trabalho (subeixo 2.1), conceito discutido por Oliveira (2004), e sua relação com as reformas educacionais ocorridas nas duas últimas décadas foi termo recorrente tratado em 112 pesquisas, destacando-se nos textos de Mazzini (2017); Silva (2017); Lennert (2009); Lima (2015); Aquino (2009); Brito (2013); Carvalho (2016); Moura (2013); Basílio (2015) e Catini (2008). Já o termo flexibilização (subeixo 2.2), mencionado por Oliveira (2004, p. 1140) como parte do processo de precarização do trabalho, apareceu em 105 pesquisas, as quais se referiram ao desmonte das condições e 
relações de trabalho, uma vez que as normas contratuais alteradas num cenário de reestruturação do Estado ampliaram as possibilidades de contratações temporárias e em condições desiguais frente aos demais trabalhadores da educação. Sobre o referido termo, destacaram-se as pesquisas realizadas por Aranha (2007); Filgueira (2017); Rigolon (2013); Santos (2016a); Santos (2016b) e Fontana (2008).

A intensificação (subeixo 2.3), outro aspecto relativo à caracterização atual do trabalho docente, resultante da maior responsabilização e ampliação das atividades destinadas aos docentes (DUARTE, 2011), foi mencionada como elemento geral apresentado na caracterização do trabalho em 102 pesquisas, sendo foco central de análise, porém, em apenas duas delas, caso de Merguedicthian (2012) e Oliveira (2017). A proletarização (subeixo 2.4) foi discutida como parte do contexto no qual está inserido o trabalho docente em 53 pesquisas, mas foi objeto direto de investigação em apenas quatro delas, sendo que se concentraram neste grupo as análises que relacionaram proletarização à organização docente, destacando-se especialmente a questão sindical, o que foi feito por Reis (2006); Fossaluzza (2017); Hidaka (2012); Notário (2007) e Lanza (2010.

Sobre o terceiro eixo de análise no qual foram agrupadas as pesquisas que trataram mais diretamente dos impactos das medidas reformistas no trabalho docente, identificamos uma predominância de investigações de natureza empírica, indicando a preocupação dos pesquisadores em dar voz aos trabalhadores docentes para compreender como as decisões ecoam na sala de aula e nos espaços escolares como um todo. Dessa forma, três subeixos se destacaram. O primeiro deles tratou das regulações educacionais assumidas por nós como "processos múltiplos, por vezes contraditórios, de orientação das condutas dos atores e de definição das "regras do jogo" no sistema social" (MAROY, 2010, p. 1) ou, ainda como definido por Barroso (2006), como o conjunto de ações do sistema educativo que envolve o controle e o ajustamento permanente a fim de assegurar o equilíbrio, de modo que convivam "uma regulação 'estatal, burocrática, administrativa' e uma regulação 'profissional, corporativa, pedagógica', que podem estar em tensão".

As regulações foram citadas em 106 pesquisas e, dentre estas, destacaram-se aquelas que abordaram as avaliações externas como foco de investigação direta (28 pesquisas), tais como as realizadas por Chirinéa (2010); Colombo (2015); Buoro (2013); Nogueira (2015); Martins (2015); Parro (2016); Silva (2016); Hojas (2017); Jesus (2014); Rubini (2017); Nallo (2010); Polato (2014); Greve (2017), Oliveira Jr., (2013); Silva (2006); Perboni, (2016); Filipe, (2016) e Ribeiro, (2008). Ainda vinculadas a este subeixo, mas tratando das alterações curriculares provocadas pela implantação de um sistema de avaliação externa que levou à padronização do que e como ensinar, estavam 34 pesquisas, destacando-se as realizadas por Ferin (2015); Giavara (2012); Leite (2011); Marques (2014); Nunes (2014) e Oliveira (2012).

Outra medida adotada pelo governo paulista no ciclo de reformas que se tornou alvo das investigações analisadas foi a bonificação por desempenho (subeixo 3.2), medida criada no início dos anos 2000 e que foi um incisivo elemento performático que alterou ritos, regras e normas no interior das escolas (FERNANDES, 2009; CUNHA, BARBOSA e FERNANDES, 2015). O termo bonificação apareceu em 94 pesquisas, tendo sido objeto específico de estudos para Bergo (2016), Vasconcelos (2006) e Alcantara (2010). Outras pesquisas importantes trataram de modo significativo o bônus, tendo como foco de estudo, entretanto, o salário, os vencimentos, a remuneração e os planos de carreira do magistério paulista, caso dos trabalhos realizados por Thomazini (2016); Barbosa (2011); Cassettari (2010).

A análise realizada neste recorte de tempo e espaço, estado de São Paulo, 1996 a 2018, trouxe elementos fundamentais acerca do trabalho docente como campo de estudos que se ampliou e se consolidou nas últimas duas décadas, movimento que acompanhou a intensificação e a complexificação das reformas educacionais de direcionamento gerencial e performático.

\section{CONSIDERAÇÕES FINAIS}

A escrita deste texto de natureza acadêmica respaldou-se em revisão bibliográfica pautada em método científico que, a partir de abordagem quali-qualitativa, visou apresentar um mapeamento e análise sobre o trabalho docente no estado de São Paulo, no período de 1996 a 2018, momento que coincide com as reformas educacionais promovidas pelo partido político que se encontra no poder há 
mais de vinte anos. Assim, esta revisão bibliográfica configurou-se não apenas como estudo de um compilado de pesquisas, mas, sim, como possibilidade de compreensão da categoria trabalho docente nos estudos realizados no estado mais rico e com maior rede pública de ensino do País, estado em que também foi se sucedendo e se consolidando um projeto educacional que tem servido de base para outras regiões do Brasil. O conjunto de pesquisa analisado indicou claramente os efeitos no cotidiano escolar de uma política que há anos implanta medidas de cima para baixo, não deixando o trabalho docente incólume, já que, além de alterar as possibilidades de constituição de um processo de autonomia, modificaram negativamente suas condições e relações de trabalho.

As análises identificadas no corpus selecionado apontaram a força das medidas advindas dos setores empresariais que foram sendo adaptadas para o espaço escolar, provocando redução da autonomia docente, aumento das responsabilidades pedagógicas e da responsabilização docente, ampliação de controle direto e indireto sobre o trabalho, competição entre os pares por vantagens salariais, intensificação e flexibilização contratual com novos processos de precarização do trabalho. Grande parte dessas pesquisas utilizou a abordagem metodológica qualitativa com ênfase em estudos empíricos, trazendo à tona processos, condições e relações de trabalho que se reestruturaram frente a um intenso movimento de reformas educacionais que, embora não esteja restrito ao estado de São Paulo, tem neste um de seus principais exemplares de reorganização de rede pública com base em princípios gerenciais. Este dado, que consideramos importante, pode ser discutido frente à necessidade de no campo específico do trabalho docente, após vários anos de sucessivas reformas educacionais, serem realizados estudos estatísticos, quantitativos e longitudinais sobre a educação pública em diferentes estados brasileiros.

A revisão bibliográfica sinalizou ainda marcante preocupação das pesquisas em compreender o trabalho docente tendo como foco a atuação em sala de aula, o que denotou, por um lado, destaque à vOz dos professores que, por meio de entrevistas, questionários e observações, foram sujeitos centrais nas investigações; mas, por outro lado, este dado pode indicar uma visão reducionista de trabalho docente, minimizando-o à atuação do professor, o que não se coaduna com a categoria analítica que o concebe como complexo, amplo e não restrito à atividade em sala de aula. Os dados de pesquisa apresentados no presente artigo têm a pretensão de contribuir para novos estudos no campo do trabalho docente, no sentido de elucidar processos que impactam os trabalhadores docentes em diferentes lugares do País, uma vez que o receituário que tem guiado os programas e projetos, com novos desdobramentos para o trabalho, é muito semelhante, a despeito das singularidades e especificidades apresentadas pelas redes de ensino.

\section{REFERÊNCIAS}

ALVES-MAZZOTTI, A. J.; GEWANDSZNAJDER, F. O método nas ciências naturais e sociais: pesquisa qualitativa e quantitativa. 2. ed. São Paulo: Pioneira Thomson Learning, 2002.

BALL, S. Profissionalismo, Gerencialismo e Performatividade. Cadernos de Pesquisa, São Paulo, v. 34, n. 126, p. 539-64, set./dez. 2005.

BARBOSA, A.; JACOMINI, M. A.; FERNANDES, M. J. S.; SANTOS, J. B. S.; NASCIMENTOS, A. P. S. Relações e condições de trabalho dos professores paulistas (1995-2018). Cadernos de Pesquisa, São Paulo, v. 50, n. 177, p. 790-812, jul./set. 2020.

BARBOSA, A.; FERNANDES, M. J. S.; O piso salarial em São Paulo: desvalorização dos professores. Revista Retratos da Escola, Brasília, v. 10, n. 18, p. 243-57, jan./jun. 2016.

BARROSO, J. O Estado e a educação: a regulação transnacional, a regulação nacional e a regulação local. In: BARROSO, J. (Org.). A regulação das políticas públicas de educação: espaços, dinâmicas e actores. Lisboa: Educa, 2006. p. 41-70. 
BORGHI, R. Municipalização do ensino fundamental e valorização docente. Educação Unisinos, v. 11, p. 163-173, 2007.

BRASIL. Ministério da Administração e Reforma do Estado (MARE). Plano Diretor da Reforma do Aparelho de Estado. Brasília, 1995.

CUNHA, R. C. B.; BARBOSA, A.; FERNANDES, M. J. S. Implicações das avaliações externas para o trabalho docente coletivo. Estudos em Avaliação Educacional, São Paulo, v. 26, n. 62, p. 386-416, maio/ago. 2015.

DUARTE, A. M. C. Políticas educacionais e trabalho docente na atualidade: tendências e contradições. In: OLIVEIRA, D. A.; DUARTE, A. (Orgs.). Políticas Públicas e Educação: regulação e conhecimento. Belo Horizonte: Fino Traço, p. 161-182, 2011.

FERNANDES, M. J. S. As recentes reformas educacionais na visão dos professores. Educação em Revista, v. 26, n. 3, p. 75-102, 2010.

FERNANDES, M. J. S. Da articulação do trabalho coletivo ao controle do trabalho docente: os (des)caminhos legais da coordenação Pedagógica no estado de São Paulo. Comunicações, v. 25, nº 3, p. 67-80, set.-dez. 2018.

FERNANDES, M. J.S.; BARBOSA, A. O trabalho docente na rede pública do Estado de São Paulo: apontamentos iniciais para a discussão da jornada de trabalho. Práxis Educacional, v. 10, n. 17, p. 117-42, 2014.

HYPOLITO, A. M. Reorganização Gerencialista da Escola e Trabalho Docente. Educação: Teoria e Prática, v. 21, n. 38, p. 1-18, out./dez. 2011.

MANCEBO, D. Agenda de pesquisa e opções teórico-metodológicas nas investigações sobre trabalho docente. Educação \& Sociedade, Campinas, v. 28, n. 99, p. 466-82, maio/ago. 2007.

MARIN, A. J.; BUENO, J. G. A escola fundamental e a Didática: a produção acadêmica e sua contribuição para o ensino. In: MARIN, A. J.; BUENO, J. G. (Org.). A escola fundamental e a didática: a produção acadêmica e sua contribuição para o ensino. Araraquara, SP: Junqueira \& Marin, p. 18-74. 2017.

MARIN, A. J. Precarização do trabalho docente. In: OLIVEIRA, D. A.; DUARTE, A. M. C.; VIEIRA, L. M. F. Dicionário: trabalho, profissão e condição docente. Belo Horizonte: UFMG, p. 1-2. 2010. CD-ROM.

MAROY, C. Regulação dos sistemas educativos. In: OLIVEIRA, D. A.; DUARTE, A. M. C.; VIEIRA, L. M. F. Dicionário: trabalho, profissão e condição docente. Belo Horizonte: UFMG, p. 1-4. 2010. CD-ROM.

MOROSINI, M. C.; FERNANDES, C. M. B. Estado do Conhecimento: conceitos, finalidades e interlocuções. Educação por Escrito, Porto Alegre, v. 5, n. 2, p. 154-64, jul./dez. 2014.

OLIVEIRA, D. A.; VIEIRA, L. F. Trabalho na Educação Básica: a condição docente em sete estados brasileiros. Belo Horizonte: Traço Fino, 2012. 
OLIVEIRA, D. A. A reestruturação do trabalho docente: precarização e flexibilização. Educação \& Sociedade, Campinas, v. 25, n. 89, p. 1127-1144, set./dez. 2004.

SOUZA, A. N. As políticas educacionais para o desenvolvimento e o trabalho docente. 1999. 203 f. Tese. (Doutorado em Educação) - Faculdade de Educação, Universidade Estadual de Campinas, Campinas, 1999.

STOCCO, S.; JACOMINI, M. A. Política Educacional na Rede Estadual Paulista (1995-2018). Relatório de pesquisa. São Paulo, p. 3-13, 2020.

TARDIF, M. O trabalho docente: elementos para uma teoria da docência como profissão de interações humanas. Rio de Janeiro: Vozes, 2005.

VENCO, S. Precariedade: desdobramentos da Nova Gestão Pública no trabalho docente. In: Crítica e sociedade, v. 6, n. 1, p. 72-90, 2016.

Teses e dissertações analisadas

ALCANTARA, M. S. Políticas de bonificação e indicadores de qualidade: mecanismos de controle nas escolas estaduais paulistas. 2010. 94 f. Dissertação (Mestrado em Educação: História, Política, Sociedade) - Pontifícia Universidade Católica de São Paulo, São Paulo, 2010.

ALMEIDA, C. S. O Processo formativo do Programa Ler e Escrever: Uma análise da rede de formações proposta pelo Estado de São Paulo. 102 f. Dissertação (Mestrado em Educação) - Pontifícia Universidade Católica de Campinas, Campinas, 2014.

ANTONINI, V. L. Banco Mundial e política educacional brasileira: um olhar sobre o Fundescola e o Plano de Desenvolvimento da Escola (PDE). 115 f. Dissertação (Mestrado em Educação Escolar) - Faculdade de Ciências e Letras, Universidade Estadual Paulista, Araraquara, 2006.

AQUINO, L. L. A. O Trabalho Docente para além do ensino: O uso do tempo destinado ao preparo de aula por professoras alfabetizadoras de escola estadual de Ciclo I do Ensino Fundamental. 132 f. Dissertação (Mestrado em Educação Escolar) - Faculdade de Ciências e Letras, Universidade Estadual Paulista, Araraquara, 2009.

ARANHA, W. L. A. Professores Eventuais nas Escolas Estaduais Paulistas: Ajudantes de Serviço Geral da Educação? 102 f. Dissertação (Mestrado em Educação Escolar) - Faculdade de Ciências e Letras, Universidade Estadual Paulista, Araraquara, 2007.

BARBOSA, A. Os salários dos professores brasileiros: implicações para o Trabalho Docente. 2011. 208 f. Tese (Doutorado em Educação Escolar) - Faculdade de Ciências e Letras, Universidade Estadual Paulista, Araraquara, 2011.

BASÍLIO, M. R. Valorização do Trabalho Docente ou uma miríade de novas responsabilidades e exigências ao professor nos decretos do governo paulista? 130 f. Dissertação (Mestrado em Educação) - Instituto de Biociências, Universidade Estadual Paulista, Rio Claro, 2015.

BENDRATH, E. A. O Programa Escola da Família enquanto Política Pública: Políticas Compensatórias e Avaliação de Rendimento. 198 f. Dissertação (Mestrado em Educação) - Faculdade de Ciências e Tecnologia, Universidade Estadual Paulista, Presidente Prudente, 2010. 
BERGO, L. F. Política de bonificação salarial no Estado de São Paulo: Desdobramentos para o desenvolvimento profissional e o Trabalho Docente. 115 f. Dissertação (Mestrado em Educação) Universidade Federal de São Carlos, São Carlos, 2016.

BUORO, E. Avaliação da aprendizagem nos ciclos e na progressão continuada a partir das concepções de atores do processo educacional. 151 f. Dissertação (Mestrado em Educação) Pontifícia Universidade Católica de Campinas, Campinas, 2013.

CARVALHO, S. R. Políticas neoliberais e educação pós-moderna no ensino paulista. 2010. 133 f. Dissertação (Mestrado em Educação Escolar) - Faculdade de Ciências e Letras, Universidade Estadual Paulista, Araraquara, 2010.

CARVALHO, S. R. Profissionalização docente e subordinação do trabalho educativo à lógica flexível da produção capitalista. 238 f. Tese (Doutorado em Educação Escolar) - Faculdade de Ciências e Letras. Universidade Estadual Paulista, Araraquara, 2016.

CASSETTARI, N. Remuneração variável para professores: revisão da literatura e desdobramentos no Estado de São Paulo. 130 f. Dissertação (Mestrado em Educação) - Faculdade de Educação, Universidade de São Paulo, São Paulo, 2010.

CATINI, C. R. Trabalho Docente, capital e Estado: crítica de interpretações sobre o magistério no Brasil. 165 f. Dissertação (Mestrado em Educação) - Faculdade de Educação, Universidade de São Paulo, São Paulo, 2008.

CHIRINÉA. A. M. O Índice de Desenvolvimento da Educação Básica (Ideb) e as dimensões associadas à qualidade da educação na escola pública municipal. $121 \mathrm{f}$. Dissertação (Mestrado em Educação) - Faculdade de Filosofia e Ciências, Universidade Estadual Paulista, Marília, 2010.

COLOMBO, B. Prova Brasil e SARESP: Repercussões na construção da qualidade da educação na percepção de professores e gestores de escolas públicas estaduais do município de Campinas (SP). 156 f. Dissertação (Mestrado em Educação) - Pontifícia Universidade Católica de Campinas, Campinas, 2015.

FERIN, E. M. O currículo de geografia do Ensino Médio das escolas públicas estaduais de São Paulo: implicações do uso de competências. 139 f. Dissertação (Mestrado em Educação) - Faculdade de Ciências Humanas, Universidade Metodista de Piracicaba, Piracicaba, 2015.

FERNANDES, M. J. S. A coordenação pedagógica em face das reformas escolares paulistas (1996-2007). 282 f. Tese (Doutorado em Educação Escolar) - Faculdade de Ciências e Letras, Universidade Estadual Paulista, Araraquara, 2008.

FERRARESI, P. D. Ensino Fundamental de nove anos: uma ampliação de direitos? $215 \mathrm{f}$. Dissertação (Mestrado em Educação) - Faculdade de Educação, Universidade de São Paulo, São Paulo, 2015.

FERREIRA, M. L. Análise da política de integração escola - comunidade: um estudo de caso do Programa Escola da Família do Estado de São Paulo. 194 f. Dissertação (Mestrado em Educação) Faculdade de Educação, Universidade Estadual de Campinas, Campinas, 2009.

FILGUEIRA, V. Condições de Trabalho Docente no Ensino Fundamental II na rede estadual paulista e representações de professores sobre autonomia. $175 \mathrm{f}$. Dissertação (Mestrado em 
Educação) - Escola de Filosofia, Letras e Ciências Humanas, Universidade Federal de São Paulo, Guarulhos, 2017.

FILIPE, F. A. A concepção de qualidade educacional induzida pelas avaliações em larga escala: análise de documentos oficiais do Estado de São Paulo (2008-2014). 229 f. Dissertação (Mestrado em Educação) - Instituto de Biociências, Universidade Estadual Paulista, Rio Claro, 2016.

FONTANA, C. A. O trabalho informal docente na rede pública de ensino do Estado de São Paulo. 150 f. Dissertação (Mestrado em Educação) - Faculdade de Ciências Humanas, Universidade Metodista de Piracicaba, Piracicaba, 2008.

FOSSALUZZA, J. T. S. A memória-trabalho e política de professores da educação básica e a consciência de classe proletária potencial. 243 f. Tese (Doutorado em Educação Escolar) Faculdade de Ciências e Letras, Universidade Estadual Paulista, Araraquara, 2017.

FREITAS, P. F. Usos das avaliações externas: concepções de equipes gestoras de escolas da Rede Municipal de Ensino de São Paulo. 194 f. Dissertação (Mestrado em Educação) - Faculdade de Educação, Universidade de São Paulo, São Paulo, 2014.

FURTADO, E. L. M. Políticas educacionais e gestão democrática na escola. 119 f. Dissertação (Mestrado em Educação) - Faculdade de Filosofia e Ciências, Universidade Estadual Paulista, Marília, 2005.

GIAVARA, A. P. Entre o discurso e a prática: a implementação do currículo de história para o ensino médio no Programa Educacional "São Paulo Faz Escola". 206 f. Dissertação (Mestrado em Educação) - Faculdade de Filosofia e Ciências, Universidade Estadual Paulista, Marília, 2012.

GREVE, L. F. Saresp e Enem: Efeitos no currículo do ensino médio integral em escolas públicas estaduais do município de Campinas na percepção de gestores e professores. $239 \mathrm{f}$. Dissertação (Mestrado em Educação) - Pontifícia Universidade Católica de Campinas, Campinas, 2017.

HIDAKA, R. K. As Políticas Neoliberais dos Governos Covas e Alckmin (1995-2006) e o Movimento Sindical dos Professores do Ensino Oficial do Estado de São Paulo. 150 f.

Dissertação (Mestrado em Educação) - Faculdade de Filosofia e Ciências, Universidade Estadual Paulista, Marília, 2012.

HOJAS, V. F. SARESP: a escola como produtora de políticas. $131 \mathrm{f}$. Tese (Doutorado em Educação) - Faculdade de Filosofia e Ciências, Universidade Estadual Paulista, Marília, 2017.

IGNÁCIO, C. M. V. O programa ler e escrever e o ensino de matemática nos anos iniciais da rede pública de São Paulo. 174 f. Dissertação (Mestrado em Educação). Faculdade de Educação. Universidade Estadual de Campinas, Campinas, 2014.

JARDIM, K. S. M. O Trabalho Docente na rede estadual de ensino no Estado de São Paulo. 174 f. Tese. (Doutorado em Educação) - Faculdade de Educação, Universidade Estadual de Campinas, Campinas, 2016.

JESUS, J. C. O Sistema de Avaliação de Rendimento Escolar do Estado de São Paulo (Saresp) e suas Implicações no Contexto de uma Escola Estadual No Município de Osvaldo Cruz/SP. 171 f. Dissertação (Mestrado em Educação) - Faculdade de Ciências e Tecnologia, Universidade Estadual Paulista, Presidente Prudente, 2014. 
LANZA, F. F. S. Gestão democrática, sindicato e participação política dos professores. 169 f. Dissertação (Mestrado em Educação) - Faculdade de Filosofia e Ciências, Universidade Estadual Paulista, Marília, 2010.

LANZA, M. L. Sobre o bom professor: estudo de caso em uma escola da rede estadual paulista com alunos do Ensino Médio. 185 f. Dissertação (Mestrado em Educação) - Escola de Filosofia, Letras e Ciências Humanas, Universidade Federal de São Paulo, Guarulhos, 2016.

LEITE, E. A. Impacto da Reforma Curricular do Estado de São Paulo (Gestão 2007-2010) em uma unidade escolar da rede. 116 f. Dissertação (Mestrado em Educação: Currículo) - Pontifícia Universidade Católica de São Paulo, São Paulo, 2011.

LEME, M. A. Programa Escola da Família: Gestão Democrática nas Escolas Públicas Paulistas? 317 f. Dissertação (Mestrado em Educação) - Instituto de Biociências, Universidade Estadual Paulista, Rio Claro, 2007.

LENNERT, A. L. Professores de Sociologia: relações e condições de trabalho. 129 f. Dissertação (Mestrado em Educação) - Faculdade de Educação, Universidade Estadual de Campinas, Campinas, 2009.

LIMA, P. M. P. Concepção e valorização do Trabalho Docente: políticas meritocráticas na educação pública. 143 f. Dissertação (Mestrado em Educação) - Faculdade de Educação. Universidade Estadual de Campinas, Campinas, 2015.

MARQUES, M. V. O Processo de Configuração Curricular: Uma Análise da Compreensão de Professores de Educação Física das Séries Iniciais do Ensino Fundamental. 119 f. Dissertação (Mestrado em Educação) - Instituto de Biociências, Universidade Estadual Paulista, Rio Claro, 2014.

MARTINS, Priscila. P. U. Políticas públicas de avaliação na perspectiva docente: desdobramentos da Provinha Brasil, Prova Brasil e Saresp para o trabalho de professores dos anos iniciais do ensino fundamental. 148 f. Dissertação (Mestrado em Educação) - Universidade Federal de São Carlos, São Carlos, 2015.

MATTOS, R. A política educacional no Estado de São Paulo (2007-2010) e suas articulações com o Trabalho Docente. 171 f. Dissertação (Mestrado em Educação) - Faculdade de Ciências Humanas, Universidade Metodista de Piracicaba, Piracicaba, 2012.

MERGUEDiCTHiAN, A. A. Plano de Carreira do professor da rede de Educação Básica do Estado de São Paulo: expectativas e atendimento. 142 f. Dissertação (Mestrado em Educação: História, Política, Sociedade) - Pontifícia Universidade Católica de São Paulo, São Paulo, 2012.

MIGUEL, K. C. D. Programa Mais Educação: uma análise do projeto pedagógico. 125 f. Dissertação (Mestrado em Educação) - Instituto de Biociências, Universidade Estadual Paulista, Rio Claro, 2015.

MOREIRA, E. E. A reforma educacional paulista entre 1995-2000 e o Trabalho Docente. 155f. Dissertação (Mestrado em Educação) - Faculdade de Ciências Humanas, Universidade Metodista de Piracicaba, Piracicaba, 2007.

MOURA, C. B. A Precarização do Trabalho Docente nas escolas estaduais paulistas. $127 \mathrm{f}$. Dissertação (Mestrado em Educação) - Faculdade de Filosofia e Ciências, Universidade Estadual Paulista, Marília, 2013. 
NALLO, R. C. Z. Avaliação externa: estratégias de controle ou inclusão?. 110 f. Dissertação (Mestrado em Educação) - Faculdade de Ciências e Tecnologia, Universidade Estadual Paulista, Presidente Prudente, 2010.

NOGUEIRA, D. C. Revisitando o espaço escolar: os sentidos produzidos pelos professores sobre o Saresp na escola prioritária. 181 f. Dissertação (Mestrado em Educação) - Universidade Federal de São Carlos, Sorocaba, 2015.

NOTÁRIO, A. C. S. Autonomia do Trabalho Docente na Rede Pública Paulista: política educacional e resistência sindical. 144 f. Dissertação (Mestrado em Educação) - Faculdade de Educação e Letras. Universidade Metodista de São Paulo, São Bernardo do Campo, 2007.

NUNES, J. L. F. A reforma da educação pública paulista dos anos 90: O discurso oficial e a ação prática do governo estadual para implementar a política do Banco Mundial. 225 f. Dissertação

(Mestrado em Educação: Currículo) - Pontifícia Universidade Católica de São Paulo, São Paulo, 2005.

NUNES, P. S. Reforma curricular na rede estadual de ensino de São Paulo: decorrências para a organização do trabalho em uma escola 210 f. Dissertação (Mestrado em Educação) - Faculdade de Educação, Universidade de São Paulo, São Paulo, 2014.

OLIVEIRA, B. P. O essencial é invisível aos olhos: a emulação à escola produtivista e a subsunção das múltiplas jornadas das professoras no programa de Ensino Integral de São Paulo. 142 f.

Dissertação (Mestrado em Educação) - Instituto de Biociências, Universidade Estadual Paulista, Rio Claro, 2017.

OLIVEIRA JR., R. G. Sistema de Avaliação de Rendimento Escolar do Estado de São Paulo: Um estudo a partir da produção científica brasileira (1996-2011). 152 f. Dissertação (Mestrado em Educação) - Pontifícia Universidade Católica de Campinas, Campinas, 2013.

OLIVEIRA, C. M. S. As implicações da implementação do currículo oficial do Estado de São Paulo no cotidiano de uma escola. 176 f. Dissertação (Mestrado em Educação) - Faculdade de Ciências e Tecnologia, Universidade Estadual Paulista, Presidente Prudente, 2012.

OLIVEIRA, L. R. Perfil e visão de trabalho expressa por professores eventuais de escolas de uma Diretoria de Ensino da Rede Estadual de São Paulo. 92 f. Dissertação (Mestrado em Educação: História, Política, Sociedade) - Pontifícia Universidade Católica de São Paulo, São Paulo, 2010.

OLIVEIRA, E. S. S. O Projeto “A Escola de Cara Nova na era da informática” na Diretoria de Ensino Região de Bauru - SP: análise de seu desenvolvimento. 139 f. Dissertação (Mestrado em Educação) - Faculdade de Ciências Humanas. Universidade Metodista de Piracicaba, Piracicaba, 2007.

PARENTE, J. M. Gerencialismo e Performatividade na Gestão Educacional do Estado de São Paulo. 135 f. Tese (Doutorado em Educação) - Faculdade de Ciências e Tecnologia, Universidade Estadual Paulista, Presidente Prudente, 2016.

PARRO, A. L. G. Avaliação Externa, Gestão e Qualidade a Educação Escolar: concepções veiculadas e concepções vivenciadas no cotidiano escolar. 165 f. Tese (Doutorado em Educação) Faculdade de Filosofia e Ciências, Universidade Estadual Paulista, Marília, 2016. 
PENNA, M. G. O. O professor de séries iniciais do ensino fundamental de escolas públicas de São Paulo: Posições sociais e condições de vida e trabalho. 307 f. Tese (Doutorado em Educação: História, Política, Sociedade) - Pontifícia Universidade Católica de São Paulo, São Paulo, 2007.

PERBONI, F. Avaliações externas e em larga escala nas redes de educação básica dos estados brasileiros. 268 f. Tese (Doutorado em Educação) - Faculdade de Ciências e Tecnologia, Universidade Estadual Paulista, Presidente Prudente, 2016.

PINHEIRO, P. V. O Banco Mundial e a Educação no Brasil: Estudo realizado a partir das teses defendidas na Universidade Estadual de Campinas (Unicamp), no período de 1995 a $2007.121 \mathrm{f}$. Dissertação (Mestrado em Educação) - Faculdade de Educação e Letras. Universidade Metodista de São Paulo, São Bernardo do Campo, 2010.

PIOLLI, G. P. Z. A Reforma educacional do ensino médio no Estado de São Paulo e os atuais desafios dos docentes. 232 f. Dissertação (Mestrado em Educação) - Faculdade de Educação, Universidade Estadual de Campinas, Campinas, 2006.

POLATO, A. A Relação entre as avaliações em larga escala e a organização do trabalho escolar em duas escolas públicas estaduais do interior de São Paulo. 172 f. Dissertação (Mestrado em Educação) - Instituto de Biociências, Universidade Estadual Paulista, Rio Claro, 2014.

RAAB, Y. S. Escola para quê? reflexões sobre a função da escola pública estadual paulista. 142 f. Dissertação (Mestrado em Educação) - Faculdade de Ciências Humanas, Universidade Metodista de Piracicaba, Piracicaba, 2016.

REGALO, C. A. Educação, escola e sociedade no Brasil: matrizes históricas, determinações políticas e estigmas institucionais da reforma neoliberal (1996-2006) e de suas implicações pedagógicas e curriculares. 209 f. Tese (Doutorado em Educação) - Faculdade de Educação, Universidade Estadual de Campinas, Campinas, 2013.

REIS, R. R. O movimento docente e o debate sobre o financiamento educacional: o caso da APEOSP (1995-2002). 135 f. Dissertação (Mestrado em Educação: História, Política, Sociedade) Pontifícia Universidade Católica de São Paulo, São Paulo, 2006.

RIBEIRO, D. S. Avaliação do Rendimento Escolar do Estado de São Paulo (SARESP): A educação a serviço do capitalismo. 229 f. Dissertação (Mestrado em Educação) - Faculdade de Educação, Universidade Estadual de Campinas, Campinas, 2008.

RIGOLON, W. O. O que muda quando tudo muda? uma análise da organização do trabalho de professores alfabetizadores.. 273 f. Tese (Doutorado em Educação) - Faculdade de Educação, Universidade Estadual de Campinas, Campinas, 2013.

RODRIGUES, J. D. Z. Implicações do projeto "São Paulo Faz Escola" no trabalho de professores do Ciclo I do Ensino Fundamental.. 258 f. Dissertação (Mestrado em Educação Escolar) - Faculdade de Ciências e Letras, Universidade Estadual Paulista, Araraquara, 2010.

RUBINI, M. A. O. S. Políticas públicas de avaliação em larga escala, índice de desenvolvimento da educação básica e a organização da escola: Limites e Possibilidades. 184 f. Dissertação (Mestrado em Educação) - Faculdade de Ciências e Tecnologia, Universidade Estadual Paulista, Presidente Prudente, 2016. 
SANTOS, F. D. V. Trabalho Docente Em Escolas Estaduais Paulistas: o desafio do professor da categoria O. 153 f. Dissertação (Mestrado em Educação Escolar) - Faculdade de Ciências e Letras, Universidade Estadual Paulista, Araraquara, 2016a.

SANTOS, J. B. S. Professores temporários da rede Estadual de São Paulo: análise da política de pessoal da perspectiva orçamentária. 200 f. Dissertação (Mestrado em Educação). Escola de Filosofia, Letras e Ciências Humanas, Universidade Federal de São Paulo, Guarulhos, 2016b.

SILVA, J. C. A política educacional do governo José Serra (2007-2010): uma análise da atuação da APEOSP. 231 f. Dissertação (Mestrado em Educação). Faculdade de Educação, Universidade Estadual de Campinas, Campinas, 2013.

SILVA, L. P. F. M. Políticas de avaliação e gestão escolar: pressupostos e contradições. 143 f. Dissertação (Mestrado em Educação) - Faculdade de Filosofia e Ciências, Universidade Estadual Paulista, Marília, 2016.

SILVA, T. M. M. Entre discursos, prescrições e percepções: a (des)valorização do estatuto socioprofissional dos professores da rede estadual paulista de ensino. 219 f. Dissertação (Mestrado em Educação) - Escola de Filosofia, Letras e Ciências Humanas, Universidade Federal de São Paulo, Guarulhos, 2017.

SOUSA, F. L. Performatividade e subjetividade na gestão escolar. 204 f. Dissertação (Mestrado em Educação) - Escola de Filosofia, Letras e Ciências Humanas, Universidade Federal de São Paulo, Guarulhos, 2016.

SOUZA, A. N. As políticas educacionais para o desenvolvimento e o Trabalho Docente. 203 f. Tese (Doutorado em Educação) - Faculdade de Educação, Universidade Estadual de Campinas, Campinas, 1999.

THOMAZINI, L. Carreira e vencimento de professores da educação básica no Estado de São Paulo. 246 f. Dissertação (Mestrado em Educação) - Escola de Filosofia, Letras e Ciências Humanas. Universidade Federal de São Paulo, Guarulhos, 2016.

TORRES, T. A. R. O Projeto Escola de Tempo Integral na rede estadual de São Paulo: considerações acerca do direito à educação de qualidade. 210 f. Dissertação (Mestrado em Educação) Faculdade de Educação, Universidade de São Paulo, São Paulo, 2016.

VASCONCELOS, L. A. O bônus do professor. 154 f. Dissertação (Mestrado em Educação) Faculdade de Educação e Letras, Universidade Metodista de São Paulo, São Bernardo do Campo, 2006.

VIÇOTI, M. A. S. A política educacional da secretaria de estado da educação de São Paulo no período de 1999 a 2002: possibilidades e limites da autonomia da escola pública. 306 f. Dissertação (Mestrado em Educação) - Faculdade de Educação, Universidade Estadual de Campinas, Campinas, 2010.

VILELA, L. R. Uma análise de política educacional de ensino paulista na década de 1990. 146 f. Dissertação (Mestrado em Educação) - Faculdade de Educação, Universidade Estadual de Campinas, Campinas, 2002. 